\title{
Research on the Impetus Mechanism of Institutional Repositories
}

\author{
Jun Deng, Qiang Bi \\ School of Management Jilin University, Changchun, China , \\ dengjun9722@163.com, biqiang12345@163.com
}

\begin{abstract}
The paper gives an illustration on the concept, features, functioning and other basic problems of institutional repositories and establishes the concept model of institutional repositories. An analysis of the six major momentum factors determining the institutional repositories development and the interaction of the impetus factors of institutional repositories development are also touched upon.
\end{abstract}

\section{Preamble}

The currently unprecedented progress of modern technology in fields of information and internet has made Institutional Repositories (referred to as IR hereafter) a prime field to carry out open access theoretical and practical research. The ultimate target of IRs is the optimized share of information and knowledge through information and internet technologies and the satisfaction of users' demands for information and knowledge in a bid to promote the innovation and communication of knowledge. However, the current frustrating situation is marked by a lack of exploration and momentum for sustainable development in related fields and a deficiency in research of IRs impetus mechanism. Thus, IRs research facilitates the exploration of interrelations among related systems in terms of IRs development and provides practical value for IRs progress. Consequently, the analysis of IRs development mechanism justifiably ensures the sustainable development of IRs.

Please use the following format when citing this chapter:

Deng, J., Bi, Q., 2007, in IFIP International Federation for Information Processing, Volume 252, Integration and Innovation Oricnt to E-Socicty Volume 2, cds. Wang, W., (Boston: Springer), pp. 123-131. 


\section{Introduction to IRs and impetus mechanism}

\subsection{Synopsis on an Institutional Repository}

The cognizance of an IR concept is determined by scholars' understanding of the connotation of as well as their perspective on the field. An IR is more likely to be encyclopedic in subject coverage, representing the full range of academic fields of study, especially an IR at universities. It is undeniable that an IR is an integration of institutional intellectual products which acquires knowledge and promotes communication through the collection, storage and management of intellectual results. Thus it is justifiable to say that an IR is a system aiming at collecting, storing, administrating and offering knowledge dissemination and knowledge service. In practice, an IR is a kind of notion as well as a system. When applied as notion, it is a challenge towards traditional academic communicative system which provides a true scientific research model based upon cyber environment and re-orients the roles of authors, librarians and publishers in the process of academic communication through separating the circles in academic publishing including collection, processing and publishing. As a kind of system, an IR provides a convenient platform for authors to publish their research fruits efficiently and enables users to have access to academic resources efficaciously in a bid to enhance scientific productivity.

Consequently, an IR concept model is divided into three levels, namely, users, database storage and management and service, which is illustrated in Figure 1.

Users: It serves as the media between content-forwarder and an IR, which submits digital research results of authors or the third party.

Database storage and management: the core of an IR, which provides data storage, metadata management, data management and dissemination of data.

Service: It provides a unified interface for users, which is responsible for terminal users' interaction. Its services mainly compose data search, data browsing and data downloading.

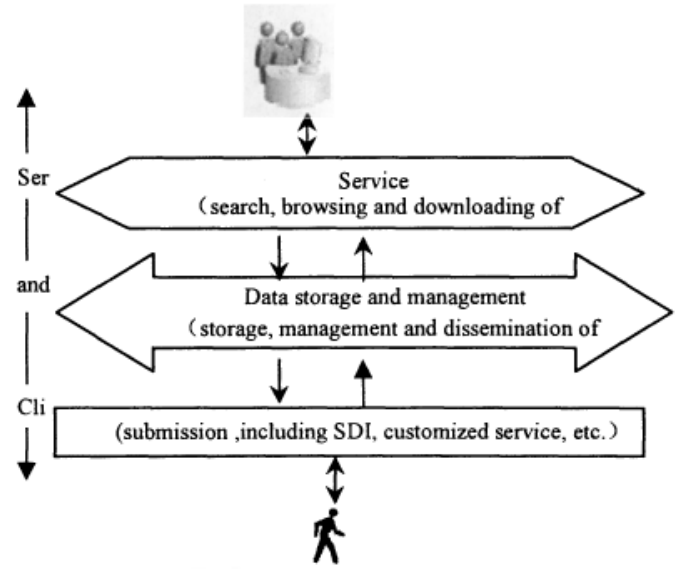

Fig. 1 the Concept model of an IR 
General speaking, there are four features in an institutional repository: institutionally defined, focused on scholarly content, cumulation and perpetuation and interoperability. Institutional repositories can create positive outcomes for all interested groups: Authors can gain visibility and enlarged research impact; users can find research more easily; institutions can raise their research profile; and the funders can receive wider research dissemination.

\subsection{Impetus Mechanism illustration}

Impetus is the factor that precipitates the progress of all existing subjects. Though originally abstract as it is the innate logic which is concealed behind all phenomena of existing things, it is practical and tangible in terms of motion, development and change. Thus impetus mechanism is the impetus which propels the progress, alteration and interaction of all of institutional repositories.

\section{Impetus Mechanism of Institutional Repositories}

The formation and development of IRs is not immediate but a long process consisting of many complicated factors including academic communication change as well as digital information resources. The impetus comes from digital information explosion's demand for the preservation of digital resources, the impulse of open access movement development, the magnetic power of the share of scientific information and knowledge, the buttress from digital information technology and standard, the support from prime institutions and theoretical as well as practical guidance from related fields( as illustrated in figure 2).

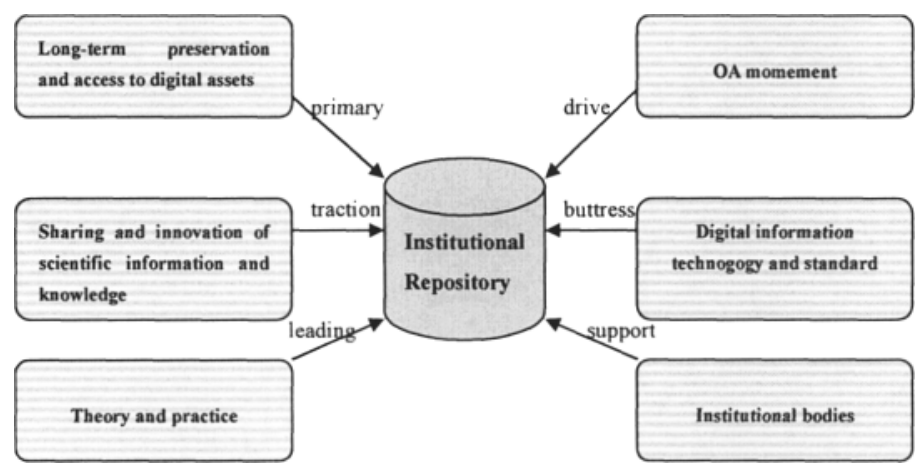

Fig. 2. Impetus Structure of development of IRs 


\subsection{The Primary Energy of IRs Lies in the Long-Term Preservation and the Storage as Well as the Access to Digital Assets}

The primary energy of an IR lies in the long-term preservation and the storage as well as the extraction of digital assets. Since the $20^{\text {th }}$ century, the development of computer technology and internet techniques is gradually modifying scholars' communicative approaches, which are not confined by traditional paper-based communicative channels. An increasing number of scholars have adopted novel communicative methods, which spawns the explosion of digital information resources. The digital information resources are distributed randomly and disorderly with the progress of digital technology and the explosive increase of digital database, hence the organization, preservation and application of digital academic assets have become the prime challenges confronted by scholars. The majority of research results are distributed online through personal cyberspace, websites and other channels, which greatly threatens the preservation and development of digital academic resources and might be inaccessible at any moment. The current situation also suffers a lack of cohesion. Confronted with the chaotic condition of digital information resources, most institutions and scholars yearn to establish an ideal storage database to realize the long-term preservation of valuable digital academic resources, consequently, an IR becomes the prime interface for the preservation and extraction of digital information.

\subsection{Open Access Movement is the Prime Impetus for the Development of IRs}

Open access serves as the prime and immediate impetus for the development and formation of IRs. Traditional publishing models greatly hinder academic development and communication with the progress of economy and technology. The price rise of serials has greatly exceeded the affordability of libraries which can only cut their limited budgets. To break price barrack hindering academic communications, open access movement has been initiated in international academic fields, publishing fields and media circles in a bid to promote the free circulation of scientific information. Two channels are available in the process of open access. one being OA, which is also called "gold" road, another being Author Self-archiving, which is also known as "Green" Road. There are two kinds of "green" OA repository: one is Subject-repository, where authors deposit in a (usually) central repository used by the community and maintained by an appropriate institution and where relevant material on a subject area is collected together; the other is an institutional repository, where the authors deposit in a repository maintained by their institution thus collecting together in one place the research output of that institution. Though open access approaches are available for some publishers and electronic journals are adopted already, it is not easy work for the creation and realization of OA and OA journals. Current figures show that only about 2,630 [1] journals are open access. Presently, the number of OA journals account for a small proportion of issued journals, as a contrast, IRs have become the main channel during the innovation of traditional academic communication system and the main solution to "scholarly communication crisis". A great deal of institutions and scholars have turned their 
eyes to the construction and development of IRs, consequently, IRs are accelerating in a startling speed with the progress of open access.

\subsection{The Sharing and Innovation of Scientific Information and Knowledge is the Impetus of IRs Development}

Communication is the key to academic research and innovation, which targets at the exploration and application of knowledge and information as well as the rejuvenation of knowledge.

In a broad sense, as the most active innovation resource in the information era, scientific information has become a vital approach in breaking through academic barriers and promoting academic integration. Scientific development demands the share of information resources, the optimization of scientific resources and the acceleration of knowledge innovation. In a narrow sense, scholars yearn to expand their influence and attract more readers, to communicate with their counterparts and to share the research results with other researchers. They also want to expand their research horizon, to keep a close eye on academic development and to perfect their research and speed up innovation. In addition, many researchers and teachers are using more informal methods for sharing such as informal networks, wikis, peer-topeer mechanisms; and providing access through owner created and managed websites. Propelled by the demand, an IR makes it emergence and consequently becomes a key factor in accelerating the pace of scientific information sharing, establishing a new order and speeding up innovations in this field.

\subsection{Digital Informational Techniques and Standards are the Pillar Force in Propelling the Development of IRs}

The support of information techniques and standards determines the path of the development of IRs as IRs emerge and develop with the development of internet technology and the progress of digital information technology and cyber environment. There is no room for its development without the support of digital information techniques. The development and perfection of related technologies is also the basis for the progress of IRs as the latter becomes a part of digital information resource management in a bid to meet scholars' demand for academic information communication and resource share. A lack of related standards will greatly impair the efficiency of IRs operation. As a consequence, the development of digital information technology and the establishment of related standards mark a profound reform in digital information field and serves as a vital determinant in IRs development. Digital information technologies carry two functions, namely, the development of digital asset management techniques, metadata description and standardization techniques. For example,

- The Open Archival Information System (OAIS) model developed by an international group of information technology organizations spearheaded by NASA's Consultative Committee for Space Data Systems, which provides a "conceptual framework for an archival system dedicated to preserving and maintaining access to 
digital information over the long run" [2], and offers "a comprehensive logical model describing all the functions required in a digital repository" [3].

- Open Archives Metadata Harvesting Protocol (OAI-PMH)[4]that was developed by the Open Archives Initiative from the library and scientific community, which defines a mechanism for harvesting XML-formatted metadata from repositories and makes the basic interoperability standard.

- A Metadata Encoding and Transmission Standard (METS) [5] developed under the sponsorship of the Digital Library Federation, which provides a schema for encoding descriptive, administrative, and structured metadata in a digital repository or library.

Another function is the development and application of open source software systems. The first step for an IR development is the design of applied software systems. The matured open source software systems that offer technical infrastructure options for implementing all or part of an institutional repository include Archimede[6], CDSware[7], DSpace[8], Eprints[9], Fedora[10], i-Tor [11], Greenstone[12] etc..

The Eprints software has the largest - and most broadly distributed - installed base of any of the repository software systems involved here, and currently over 222 [13] known archives are running on the software. The DSpace software has also generated a great deal of excitement and encouraged wave of institutions around the world to implement institutional repositories, which formed a DSpace Federation and currently over 218[14] known archives are running on the software.

These techniques make IRs resource share possible, realize the interoperability between IRs, and integrate all chaotically-distributed resources in a variety of IRs into the unified system of global information digital operation system. The development and application of open software systems also lowers the cost of the establishment of an IR for an institution. The open source software systems are regarded as the most cost-effective and immediate route to set up and advance the development of institutional repository. The standardization and techniques for digital information and the perfection of related criteria determine IRs development, the construction of digital information resources.

\subsection{Institutional Bodies are the Determinant of IRs}

The development and realization of IRs are determined by institutional body as they are inter-dependent. Its functions are embodied by the implementation of policies and financial investment. Take self-archiving mandate for example, self-archiving determines the content of an IR as an IR will be vacant without resources. To enrich IRs content resource, many institutions, governments and research organizations have established self-archiving mandate policies. According to ROARMAP [15], Statistics reveals that: three universities adopted departmental-mandate policy, ten institutions adopted institutional-mandate policy, eleven institutions adopted funder-mandate policy, six institutions adopted proposed funder-mandate policy. Besides, University of Southampton Department of Electronics and Computer Science successfully lobbied the UK Parliamentary Select Committee in 2004 to mandate self-archiving; This led directly to the RCUK self-archiving mandate 
proposal. The self-archiving mandate greatly promotes the development of IRs. Meanwhile, some governments applauding IRs development also invest great amounts of money into IRs programs and ensure their development legally. For example, in the Netherlands, the Dutch government has given 2 million Euros to setup the infrastructure for IRs at several of the Universities, the Dutch National Library, and the Dutch Academy of Arts and Sciences (Surf, 2003), which named he Digital Academic Repositories(DARE). Also the bipartisan Federal Research Public Access Act, introduced on May 2, 2006 by Senators John Cornyn (R-TX) and Joe Lieberman (D-CT), would require that 11 U.S. government agencies with annual extramural research expenditures over $\$ 100$ million make manuscripts of journal articles stemming from research funded by that agency publicly available via suitable digital repositories [16].

\subsection{Theoretical Research and Practical Development are the Impetus of the Development of IRs}

An IR development falls into two categories, namely, theoretical progress and practical progress, which are interactive and bilaterally-influential.

The Association of Research Libraries, Scholarly Publishing and Academic Resources Coalition and the Coalition for Networked Information established SPARC IR Workshop and sponsored a series of academic seminar on institutional repositories, such as the Workshop on Institutional Repositories intended to help academic and research library and IT directors and their senior staffs begin planning for the implementation of repositories in 2002, the conference on the strategies critical to implementing and managing the successful long-term growth of your institutional repository in December, 2004 and on building a successful institutional repository in April, 2005,etc.. Some interested scholars such as Raym Crow [17], Stevan Harnad[18], David Prosser[19], Clifford Lynch[20] and William Nixon discusses and researches the development tendencies of challenges and problems in a variety of fields including technology, theory, law and the like, which greatly speeds up the discussion and research of IRs development and propels the integration of practice with theory. In the UK, the Joint Information Systems Committee (JISC) is funding the development of institutional repositories for several of their leading research institutions [21]. In Canada, Twelve Canadian research libraries have begun a pilot project to implement institutional repositories, which is being coordinated by the Canadian Association of Research Libraries.

Presently, IRs are development in an unprecedented speed and have a trend of globalization. According to statistics, 862 [22] IRs have been established on a global scale, which is the vital foundation for IRs development; the academic study of IRs research deepens the theoretical research of IRs and propels the progress of IRs practice. 


\section{The Interaction of IRs Development Impetus Factors}

IRs originate from different mechanisms and the previously-mentioned six forces are interactive and form a new impetus in determining the development of IRs. From a information technology angle, digital prosperity is achieved in scientific research. With the support of institutional bodies, IRs are to witness a quick development, IRs theories are to witness a penetration and IRs practical fields are to witness an expansion. The support boosts the development and prosperity of the preservation of digital assets and the management skills. Thus IRs development is realized and coordination achieved.

\section{Conclusion and Prospects}

Comprehensively-speaking, demand and impetus are the basic power for IRs development, digital information techniques and related standards are the vital supports for IRs development. IRs progress is also determined by institutional bodies, $\mathrm{OA}$ movement and the integration of practice and theory.

What deserves special mention is that the development of IRs varies with their determinant factors. Presently, IRs are in their primary process of development and deeper research together with the establishment of related models is compulsory to enhance their popularity in society, to improve the awareness of IRs, to promote the development of IRs and to realize the communication and innovation of scientific communication.

\section{Acknowledgments}

The paper is one of the research results of the key research project funded by Ministry of Education, P.R.of China (NO.05JZD00024)

\section{Reference}

1. (April 10, 2007); http://www.doaj.org.

2. Brian Lavoie, "Meeting the Challenges of Digital Preservation: The OAIS Reference Model." 2000. OCLC Newsletter 243 (January/February): 26-30. (April 18, 2007); http $/ /$ digitalarchive. oclc.org/da/ViewObject.jsp?objid $=0000001747$

3. Preserving our digital heritage. RLG News 2003, 56 (Spring): 1-3. (April 18, 2007); http://www.rlg.org/en/pdfs/rlgnews/news56.pdf.

4. Open Archives Initiative. (April 18, 2007) http://www.openarchives.org/.

5. METS, (April 18, 2007); http://www.loc.gov/standards/mets/.

6. (April 18, 2007); http://archimede.bibl ulaval.ca/.

7. (April 18, 2007); http://cdsware.cern.ch.

8. (April 18, 2007); http://www.dspace.org/. 
9. (April 18, 2007); http://software.eprints.org/.

10. (April 18, 2007); http://www.fedora.info/.

11. (April 18, 2007); http://www.i-tor.org/en/.

12. (April 18, 2007); http:/www.greenstone.org.

13. (April 18, 2007); http://www.eprints.org/.

14. (April 18, 2007); http://wiki.dspace.org/index.php//DspaceInstances.

15. (April 18, 2007); http://www.eprints.org/openaccess/policysignup/.

16. (April 18, 2007); http://www.arl.org/sparc/advocacy/frpaa/.

17. SPARC Senior Consultant.

18. Department of Electronics and Computer Science at the University of Southampton.

19. SPARC Europe Director.

20. Director of the Coalition for Networked Information.

21. University of Nottingham, University of Edinburgh, University of Glasgow, Universities of Leeds, Sheffield and York, University of Oxford, British Library, and Arts and Humanities Data Service.

22. (April 18, 2007);http://roar.eprints.org/index.php. 